\title{
Analysis of Learning Behavior and Pattern of Online Learners on a MOOC Platform
}

\author{
G.R.K. Murthy Seema Kujur* S. Senthil Vinayagam Yashavanth B.S. \\ Ch. Srinivasa Rao Indradevi T. \\ ICAR- National Academy of Agricultural Research Management, \\ ICAR, NAARM Rd, Acharya Ng Ranga Agricultural University, \\ Rajendranagar mandal, Hyderabad, Telangana, 500030 \\ P. S. Pandey Vanita Jain \\ Indian Council of Agricultural Research, \\ Krishi Bhavan, Dr Rajendra Prasad Rd, opp. Rail Bhavan, New Delhi, Delhi 110001
}

\begin{abstract}
Understanding a learner in an online environment can ensure success of an online course. The present study determines learning behavior and learning pattern among learners on the MOOC platform established for running an online course offered at ICAR-National Academy of Agricultural Research Management (NAARM), Hyderabad, India. The demographic description and significant difference between learning patterns of the learners on MOOC according to their subject domain were analyzed by using Moodle LMS (Learning Management System). The learner group was found to comprise in majority as males or doctorate degree holders, and of agriculture domain. Most of the learners were found to be passive who were frequently engaging in the course in terms of learning behavior which indicates their way of participating in the course. Majority of the learners had moderate interest and seriousness to learn the subject. With regard to course participation which is measured in Course log-in patterns, learners with subject domains like Engineering and Agribusiness Management and Agriculture and Veterinary streams had similarity in course participation. Among the weekly participation, there was a significant increase in course participation towards course ending irrespective of subject domains which indicates the participants' urge to complete the course for certification. The key observations found through study can be of paramount importance in designing a successful MOOC with better completion rates.
\end{abstract}

Keywords: Massive Open Online Courses, Learning behavior, Learning pattern, Learning Management System. DOI: $10.7176 / \mathrm{JEP} / 12-13-03$

Publication date:May $31^{\text {st }} 2021$

\section{Introduction}

Massive Open Online Courses (MOOCs) are freely available courses offered online for distance-based learners who have access to the internet (Tucker et al 2014). It provides increasing opportunities for skills acquisition and the classes are delivered in an online environment with several features that are different from previous approaches to digital education (Alraimi et al 2015; Christensen et al 2013). There has been a surge in interests for MOOCs in recent years and more people find in MOOCs a cheap means to acquire new skills and improve their employability (Christensen et al 2013). It requires individual learners to self-regulate their learning, determining when, how and with what content and activities they engage (Hood et al 2015). According to Mukala et al (2015), successful (distinction and normal) learners perform better because they follow the videos and submit quizzes in a more structured way than unsuccessful (fail) learners. Knowing that the way learners follow videos can have a direct impact on their final performance is paramount to organize the course content and the overall structure of the course.

MOOCs attract a diverse range of learners, each with different motivations and prior experience. Online courses can offer rich, real-time data to understand and improve student learning. It also aimed at open participation, access via the web, delivered free of charge, lowering social, cultural and geographic barriers to participation. Most of the learners who enroll in MOOCs selectively engage with a part of the course content (Anderson et al 2014; Breslow et al., 2013; Evans et al 2016; Ho et al 2015; Kizilcec et al 2013; Pernaet et al 2014; Seaton et al 2014). Around $84 \%$ of learners mentioned that they had no enough time for the course. Half of the $84 \%$ who faced time issues also indicated being easily distracted from the course, which suggests that resource management strategies could have prevented their disengagement (Kizilcec \& Halawa 2015). Gender differences emerged in the use of multiple self-regulated learning courses in which particularly women were more inclined to seek help than men in contrast to prior work (Basol \& Balgalmis 2016; Liou \& Kuo 2014; Yukselturk \& Top 2013). Demographic information for MOOC courses demonstrates a strong tendency in favour of female learners compared to males (Kerr et al 2015). Numerous studies have found individual differences in learners' engagement and achievement in MOOCs. Empirical investigations have linked variation in course behavior and achievement with various individual differences in learner's demographic and personal background (Evans et al 2016; Guo \& 
Reinecke 2014; Hansen \& Reich 2015; Kizilcec \& Halawa 2015).

It was intended that the bulk of study time would be devoted to reading materials and watching videos put together by the course team and then taking part in discussions and debates, moderated by "mentors". The discussion forums were arranged with mentors for providing additional, more 'official' feedback for learners as well as debate prompts (Kerr et al 2015). MOOC has the ability to access course assessments (e.g., assignments, quizzes), discuss course learning objectives and outcomes with other learners (e.g., through an online forum) (Tucker et al 2014). In all MOOC platforms, the educational staff creates forum discussions to encourage and involve learners in discussions (Spyropoulou et al 2014). Users who are participated in forums and quizzes are presented to indicate participation levels (Wang et al 2015). At the end of some MOOC courses, a small fee may be required for issuing a course completion certificate for successful learners. Learning behavior is operationalized in the present study as learners' engagement in the course in terms of viewing course video, downloading PPT study material and self-assessment questions, participating in the discussion forum, uploading assignment and quizzes. In the present study learning pattern is conceptualized as a coherent whole of learning activities that learners usually employ, their beliefs about learning and their learning motivation, a whole that is characteristic of them in a certain period of time. It is a coordinating concept, in which the interrelationships between cognitive, affective, and regulative learning activities, beliefs about learning, and learning motivations are united (Vermunt, \& Donche, 2017). In India, MOOCs platform called SWAYAM is established to encourage online learning in all subjects. The time has arrived to understand the learner behavior in Indian context concerning different subject domains.

Massive open online courses (MOOCs) attract a large number of learner registrations, but recent studies have shown that only a small fraction of these learners complete their courses. Learners dropouts are thus a major deterrent for the growth and success of MOOCs. Understanding the learners' pattern as a course progresses is essential for minimizing dropout rates. In online environment it is challenging to recognize and measure engagement of learners in course as traditional classroom courses where engagement can be observed in person. Learners' engagement includes online activity by the learner on the course website, interactions with other learners/staff on the discussion forums, completion of quizzes/assignments. These differences make the problem of measuring learners' engagement difficult (Ramesh, et al. 2013). Thus, the need of the present study is to explore the learning behavior and pattern of the learners in MOOC which evolve the learners' high engagement to course. The analyses of learning behavior and pattern presented in this study go some way to providing greater insights into learners' activity in MOOCs.

\section{Review of Literature}

Santos et al. (2014) analysed learners' learning behaviors in MOOCs and found that learners who participated more on courses activities have a better chance to pass the course. Those learners who frequently communicated, discussed, shared, and collaborated with others showed a better learning outcome. Their study also suggested that those who posted often in discussion forum would have a higher rate of passing the course.

Anderson et al. (2014) investigated that how learners' level of engagement and activity correlated with learners' final grade which address the certification for the course. They found that the main characteristic of high-grade achievers was that they visited many lecture videos during course.

Learning behavior and patterns in MOOCs can tell us something about the types of activities that are known to be engaging. Like, Kizilcec et al. (2013) identified four prototypical learning patterns in a MOOC that consisted of watching videos and taking quizzes. These patterns were as learners who completed the majority of assessment, learners who engaged mainly in terms of watching videos, learners who did assessment at the beginning of the course, and learners who only watched videos for one or two assessment periods. Pireva, et al. (2015) asserted that the learning platforms are being used not only as an added value on technology platform for supporting the traditional learning process, but also for networking, blended, and distance learning. They have done comparison on five platforms, Moodle, Atutor and Claroline as open source and Blackboard and Fronter as commercial ones. Participants preferred Moodle amongst the LMSs for MOOCs. Participants also asserted that it is difficult to conclude whether any given platform meets all the requirements of a learner and is a solution to all the learning requirements.

Blagojević, \& Milošević (2015) concluded differences in the capabilities of EDX and Moodle MOOC and they reported that both systems support massive open online courses, but the individual segments differ regarding the features and use in terms of teachers. Moodle MOOC provides a possibility of organizing collaborative activities, through wikis and workshops. edX offers a possibility of collaborative activities for participants through the wiki, and also virtual labs are planned for more participants to work together. However, exports of these data provide more opportunities within Moodle MOOC, as compared to edX, in terms of possible formats in which the reports are exported. Visualization of the results is provided by both systems.

It may be noted that there are not much investigations done on MOOC concerning agriculture and its allied domains in comparison with other domains. Hence, the present study was taken up to study learning behavior and 
pattern in MOOCs with the following objectives:

1. To study the demographic characteristics of learners

2. To study the learning behavior of learners

3. To study the comparative login or learning pattern between subject domain learners

\section{Methods}

\subsection{Participation in the MOOC}

A month-long MOOC on Teaching Excellence with the purpose of honing the teaching skills of working and aspirant teachers was offered during November 2018 through Moodle LMS. Moodle LMS is a non-commercial elearning platform which is highly use by the people and this platform is easy to use and work with for a new user. The number of learners who enrolled in the MOOC course was 1192. The course content consisted of video lectures, reading material, PowerPoint presentations, discussion forums, and assignments. During the course period, participation in discussion and assignment submission was mandatory for the certification. The learner's learning pattern as well as performance was evaluated by participating in the discussion forums, assignment submission, and quiz. If the learners wanted to receive a certificate for completing the course, they needed to complete the quiz, complete at least two assignments, and participate at least twice in the required discussion forums. If learners wanted to receive a certificate for participation only, they needed to complete any one activity from the quiz, assignment, and discussion.

\subsection{Data Source, Sampling Technique, and Analysis}

During MOOC course period, data pertaining to learner activities has been collected from data logs of LMS. Since there is no control on the number of learners in each subject domain, stratified simple random sampling technique with proportional allocation was used for extracting a specific sample size for the data analysis. A stratified random sampling with proportional allocation involves dividing the entire population into homogeneous groups called strata. A random sample from each stratum was taken in a number proportional to the stratum's size when compared to the population. These subsets of the strata are then pooled to form a random sample. The sample size is determined as below

Sample size of the strata $=\frac{\text { Sample size }}{\text { population size }} \times$ Stratum size

Considering a total sample size of 250 out of total MOOC learner population size of 1192, the sample size for each domain worked out as follows:

Table 1. Description of sample size based on subject domain

\begin{tabular}{|l|l|l|l|}
\hline S1. No. & Subject Domain & Strata & Sample Size \\
\hline 1. & Agriculture & 796 & 167 \\
\hline 2. & Veterinary & 217 & 46 \\
\hline 3. & Agribusiness Management \& Engineering & 90 & 19 \\
\hline 4. & Education & 89 & 18 \\
\hline Total & 1192 & 250 \\
\hline
\end{tabular}

Descriptive analysis including frequency and percentage were carried out and sample mean-difference test was conducted to compare learning pattern in terms of login activities in the different subject domains. ANOVA with Post hoc test was used to determine the significant difference in the group means of learners' weekly login pattern for each subject domain.

\section{Results and Discussion}

Out of 1192 learners, 482 successfully completed the course, out of 482 learners 267 have got completion certificate and 215 have got participation certificate based on their learning pattern and level of performance in course. The learner data was thoroughly analysed to understand their learning patterns and background.

\subsection{Demographic Information}

This section explains demographic information such as Gender, Education, Subject Domain of the learners 
Table 2. Demographic information of the learners/participants in MOOC

\begin{tabular}{|c|c|c|c|}
\hline Sl. No. & Demographic Information & Frequency $(\mathrm{F})$ & Percentage (\%) \\
\hline 1. & \multicolumn{3}{|l|}{ Gender } \\
\hline & Male & 188 & 75.2 \\
\hline & Female & 62 & 24.8 \\
\hline \multirow[t]{4}{*}{2.} & \multicolumn{3}{|l|}{ Educational Qualification } \\
\hline & Bachler degree & 4 & 1.6 \\
\hline & Master degree & 98 & 39.2 \\
\hline & Doctorate degree & 148 & 59.2 \\
\hline 3. & \multicolumn{3}{|l|}{ Subject Domain } \\
\hline & Agribusiness Management & 8 & 3.2 \\
\hline & Education & 18 & 7.2 \\
\hline & Engineering & 11 & 4.4 \\
\hline & Veterinary & 46 & 18.4 \\
\hline & Agriculture & 167 & 66.8 \\
\hline
\end{tabular}

The result concluded that there is a major participant from males, which is almost three times than of females. As shown in Table 2, the majority of the learners (59.2\%) have done a doctorate in various subject domains, followed by $39.2 \%$ of the learners have done master in various subject domains such as agriculture, veterinary science, education, technology, philosophy and agribusiness management. Only $1.6 \%$ of the learners have done undergraduate degree in various subject domains. Since the learners were either students in higher education or academicians and administrators, it was expected to have a higher ratio in MOOC experience. This observation is in consonance with that of Guo and Reinecke (2014) who observed that majority of learners were post graduates in a MOOC offered on the edX platform. Generally, a massive number of learners register in MOOC for every different course and those learners belong to the various subject domain. Hence, the analysis was done to categorize learners' according toc subject domain. Result indicates that the majority of learners $(66.8 \%)$ were from the agriculture domain, followed by $18.4 \%$ from veterinary, $7.2 \%$ from education, $4.4 \%$ from engineering and $3.2 \%$ from agribusiness management.

\section{Educational Qualification}

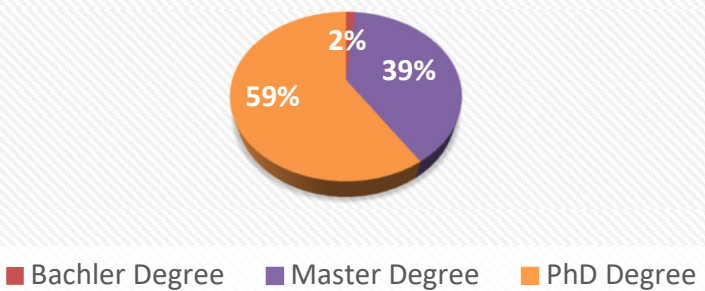

Figure 1: Distribution of the learners according to their educational qualification

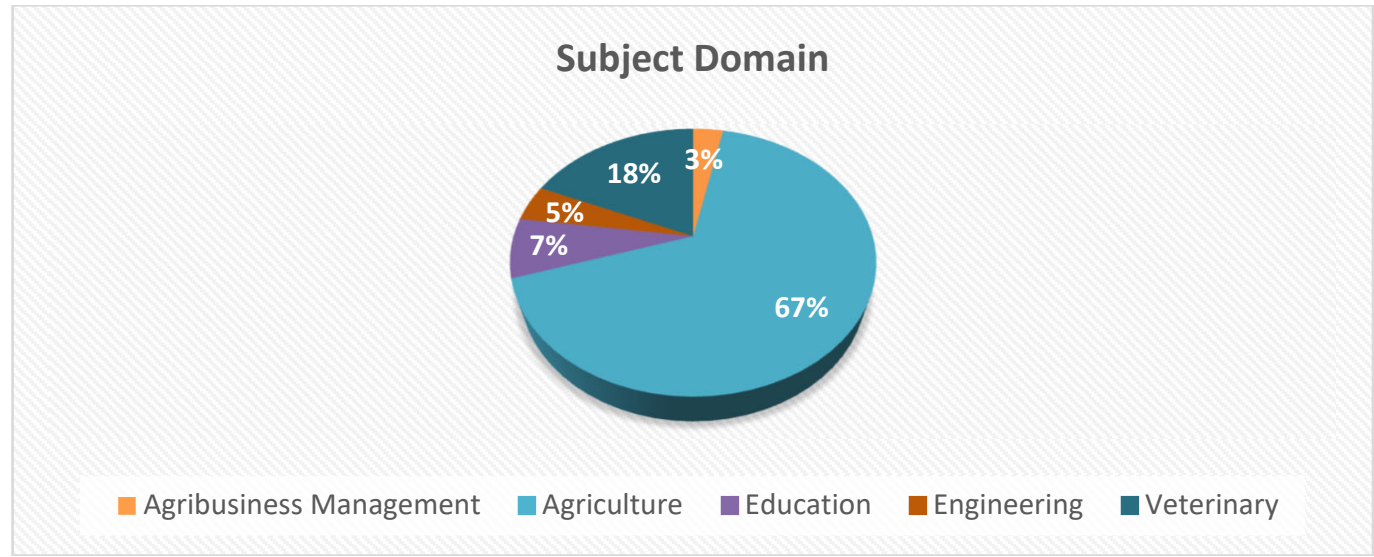

Figure 2: Distribution of the learners according to their subject domain

\subsection{Learning Behavior of the learners}

In this section, learners learning activities were investigated based on the login patterns in MOOC during the 
course period.

Learners' average login to the MOOC describes their daily activities in the MOOC such as course video viewing, participation on the discussion forum, downloading PowerPoint presentation, reading material and selfassessment questions. Types of learners have been found out by learners' average login value with categorization into three categories namely Active, Moderate and Passive learners. As shown in Table 3, majority of the learners (79.6\%) had fallen under passive types of learners with criteria of average login value $\leq 30$. It could be concluded that Passive learners were those who were periodically visiting the course which is measured by their course log pattern. About $19.2 \%$ of the learners had fallen under Moderate types of learners with average login between 3060. It indicates the learning pattern of the learners who were regularly visiting the course and completed all the requirements for certification. The least number of the learners $(1.2 \%)$ had fallen under Active types of learners with criteria of average login value $>60$. Active types of learners were those who have shown their excellent performance in the course in terms of course activities like watching video lectures, discussion fora \& assignment submission and completed the course requirement of certification.

Kahan et al. (2017) had identified seven types of learners' learning behavior in MOOCs. The Tasters and the Downloaders exhibited low levels of engagement in the course. The Disengages were moderately engaged in the course. The Online Engagers, the Offline Engagers, the Moderately Social Engagers, and the Social Engagers exhibited high levels of engagement in the course. Tseng, et al. (2016) were classified three types of MOOC learners as active learner, passive learner, and bystander. Active learners who submitted assignments on time and frequently watched lecture videos showed a higher completion rate and a better grade in the course. Completing assignments were more often among active learners than passive learners and bystanders. In all three courses, only few of bystanders had ever handed in course assignments. These findings addressed the classification of learners learning behavior in MOOCs which is relevant to the present study.

Table 3. Distribution of the learners according to their login pattern in MOOC

\begin{tabular}{|l|l|l|l|l|}
\hline Sl. No. & Types of learners & Criteria of average login value & Frequency & Percentage (\%) \\
\hline 1. & Active & $>60$ & 3 & 1.2 \\
\hline 2. & Moderate & $30-60$ & 48 & 19.2 \\
\hline 3. & Passive & $\leq 30$ & 199 & 79.6 \\
\hline Total & 250 & 100 \\
\hline
\end{tabular}

\subsection{Experimental result: Comparison between the subject domain learners with their learning patterns}

\subsubsection{Analysis of Paired sample t-Test for learning on MOOC}

The agriculture, veterinary, agribusiness management, engineering and education subject domain learners' login or learning pattern was calculated in MOOC. The paired sample t-test technique was used for comparing the means of the agriculture and veterinary domain learner's learning pattern which includes weekly average login in MOOC. The result of the paired sample t-test is displayed in Table 4 .

Hypothesis:

H0: There is no significant difference in mean of weekly average login between agriculture and veterinary domain learners and between agribusiness management, engineering and education domain learners

H1: There is a significant difference in mean of weekly average login between agriculture and veterinary domain learners and between agribusiness management, engineering and education domain learners

The results have shown for agriculture and veterinary domain learners' average login the calculated t-value and P-value were $1.613 \& 0.205$ and for agribusiness management, engineering and education domain learners' average login the calculated t-value and P-value were 3.32 and 0.045 respectively. Calculated P-value is greater than the alpha value 0.05 , so it can be concluded that there was no significant difference between agriculture and veterinary subject domain learners' weekly average login pattern in MOOC. Whereas, the p-value is less than 0.05 , there is a significant difference between ABM, engineering, and education domain learners' average login pattern. Agribusiness management, engineering domain learners had shown more active performance in terms of login pattern as compared to the education domain learners. Therefore, the null hypothesis is rejected and accepted the alternate hypothesis. 
Table 4. Paired sample t-test for weekly average login pattern between agriculture and veterinary domain learners

\begin{tabular}{|c|c|c|c|c|c|c|c|c|c|}
\hline & & \multicolumn{5}{|c|}{ Paired Difference } & \multirow[t]{3}{*}{$\mathrm{t}$} & \multirow[t]{3}{*}{$\mathrm{df}$} & \multirow{3}{*}{$\begin{array}{l}\text { Sig. (2- } \\
\text { tailed) }\end{array}$} \\
\hline & & \multirow[t]{2}{*}{ Mean } & \multirow[t]{2}{*}{$\begin{array}{l}\text { Std. } \\
\text { Deviation }\end{array}$} & \multirow[t]{2}{*}{$\begin{array}{l}\text { SE } \\
\text { Mean }\end{array}$} & \multicolumn{2}{|c|}{$\begin{array}{l}95 \% \\
\text { Confidence } \\
\text { Interval of the } \\
\text { difference }\end{array}$} & & & \\
\hline & & & & & Lower & Upper & & & \\
\hline Pair 1 & $\begin{array}{ll}\text { Average } & \text { login } \\
\text { agriculture -veterinary }\end{array}$ & 1.59 & 1.97 & 0.98 & -1.54 & 4.73 & 1.61 & 3 & $0.205^{\mathrm{NS}}$ \\
\hline Pair 2 & $\begin{array}{lr}\text { Average } & \text { login } \\
\text { agribusiness } & \\
\text { management, } \\
\text { engineering } \\
\text { education }\end{array}$ & -20.66 & 12.42 & 6.21 & -40.43 & -0.89 & -3.32 & 3 & $0.045^{*}$ \\
\hline
\end{tabular}

*Significant at 5\% level, NS= Non-significant

4.3.2 Analysis of learning pattern of agriculture and veterinary domain learners based on their gender

A comparative analysis (Tale 5) was carried out to determine significant difference in the means of the agriculture and veterinary domain male and female learner's weekly average login in MOOC.

Hypothesis:

H0: There is no significant difference in mean of average login between the agriculture domain male and female learners and between veterinary domain male and female learners in MOOC

H1: There is a significant difference in mean of average login between the agriculture domain male and female learners and between veterinary domain male and female learners in MOOC

Results show that the calculated t-value and p-value were -0.686 and 0.542 respectively for the agriculture male and female learners. Along with this the calculated t-value and P-value were 0.771 and 0.497 respectively for the veterinary male and female learners. By using the confidence interval of $95 \%$, the alpha value is 0.05 . Since the $\mathrm{P}$-value is greater than 0.05 , there is no evidence against the null hypothesis and the data appear to be consistent with the null hypothesis that there is no significant difference in means of agriculture and veterinary learner's gender-based average login in MOOC. Thus, it can be seen that that the male and female learners from agriculture and veterinary domain were showing similar course participation pattern in MOOCs.

Table 5. Paired sample test for total login pattern by agriculture domain MOOC learners

\begin{tabular}{|c|c|c|c|c|c|c|c|c|c|}
\hline & & \multicolumn{5}{|c|}{ Paired Difference } & \multirow[t]{3}{*}{$\mathrm{t}$} & \multirow[t]{3}{*}{ df } & \multirow{3}{*}{$\begin{array}{l}\text { Sig. } \\
\text { tailed) }\end{array}$} \\
\hline & & \multirow[t]{2}{*}{ Mean } & \multirow[t]{2}{*}{ SD } & \multirow[t]{2}{*}{$\begin{array}{l}\text { SE } \\
\text { Mean }\end{array}$} & \multicolumn{2}{|c|}{$\begin{array}{l}95 \% \text { Confidence } \\
\text { Interval of the } \\
\text { difference }\end{array}$} & & & \\
\hline & & & & & Lower & Upper & & & \\
\hline Pair 1 & $\begin{array}{l}\text { Weekly Average login } \\
\text { Agriculture Male- } \\
\text { Female }\end{array}$ & -3.365 & 9.81 & 4.90 & -18.98 & 12.252 & -0.686 & 3 & $0.542^{\mathrm{NS}}$ \\
\hline Pair 2 & $\begin{array}{l}\text { Weekly average } \\
\text { login Veterinary Male } \\
\text { - Female }\end{array}$ & 7.80 & 20.24 & 10.12 & -24.40 & 40.01 & .771 & 3 & $0.497^{\mathrm{NS}}$ \\
\hline
\end{tabular}

$\mathrm{NS}=$ Non-significant

\subsubsection{Analysis of Variance (ANOVA) by using Post hoc test}

ANOVA with factor replication for comparison of weekly login in different groups

ANOVA test the equality of at least three or more group means, statistically significant results indicate that not all of the group means are equal. However, ANOVA results do not identify which particular differences between pairs of means are significant. ANOVA with factor replication was conducted to determine the significant difference between or within group means among each subject domain learners' no. of login in different weeks in MOOC. The obtained result has presented in Table 6.

Hypothesis:

H0: All subject domain groups learners' learning pattern means are equal.

H1: All subject domain group learners' learning pattern means are not equal.

From the table 6 , result shown that significance or $\mathrm{P}$ value $(<0.001$ for all groups except ABM \& engineering group which is 0.010 ) is much smaller than the table value 0.05 for all subject domain group in terms of no. of login in different weeks. So, it could be concluded that there is highly significant difference between the no. of logins in different weeks for the agriculture, veterinary, agribusiness management $\&$ engineering and education 
group. It means leaners' participation to course was varying in every week. This is great to know, but it is not clear which of the specific groups differed.

Table 6. ANOVA for comparison of weekly login in different groups

\begin{tabular}{|c|c|c|c|c|c|}
\hline Source of Variation & $\begin{array}{l}\text { Degrees of } \\
\text { Freedom }\end{array}$ & $\begin{array}{l}\text { Sum of } \\
\text { Squares }\end{array}$ & $\begin{array}{l}\text { Mean Sum of } \\
\text { Squares }\end{array}$ & F value & $\operatorname{Pr}(>F)$ \\
\hline \multicolumn{6}{|l|}{ Agriculture Group } \\
\hline Login week & 3 & 397503 & 132501 & 52.28 & $<0.001$ \\
\hline Replication & 166 & 1392446 & 8388 & 3.31 & $<0.001$ \\
\hline \multicolumn{6}{|l|}{ Veterinary Group } \\
\hline Login week & 3 & 94793 & 31598 & 15.319 & $<0.001$ \\
\hline Replication & 45 & 354781 & 7884 & 3.822 & $<0.001$ \\
\hline \multicolumn{6}{|c|}{ Agribusiness Management \& Engineering Group } \\
\hline Login week & 3 & 13291 & 4430 & 4.123 & 0.010 \\
\hline Replication & 18 & 97728 & 5429 & 5.053 & $<0.001$ \\
\hline \multicolumn{6}{|l|}{ Education Group } \\
\hline Login week & 3 & 37543 & 12514 & 8.448 & $<0.001$ \\
\hline Replication & 17 & 172581 & 10152 & 6.853 & $<0.001$ \\
\hline
\end{tabular}

4.3.4 Post hoc test for agriculture, veterinary, agribusiness management $\&$ engineering and education domains weekly login pattern (Probabilities for comparison of individual week means)

Post hoc tests are an integral part of ANOVA. Post hoc tests used to explore differences between multiple groups means while controlling the experiment-wise error rate. Post hoc test ensure which particular group means is statistically significant difference among all other groups.

Post hoc test for multiple comparison with Least Significant Difference (LSD) was carried out with significance level $0.05(5 \%)$. From Table 9 the calculated significance value is very less than significance level 0.05 for agriculture, veterinary, and education group no. of login in different weeks. So, it could be concluded that there is significant difference between the no. of logins in week 4 and the number of logins in week 1,2 and 3 are on par. Whereas, agribusiness management group shows significant difference between only no. of logins in week 4 and week 1 and all others are on par. It means learners were more actively participated to MOOC at the timing of course ending may be with the purpose of getting certificate.

Table 7. Post hoc test for all subject domain (Probabilities for comparison of individual means)

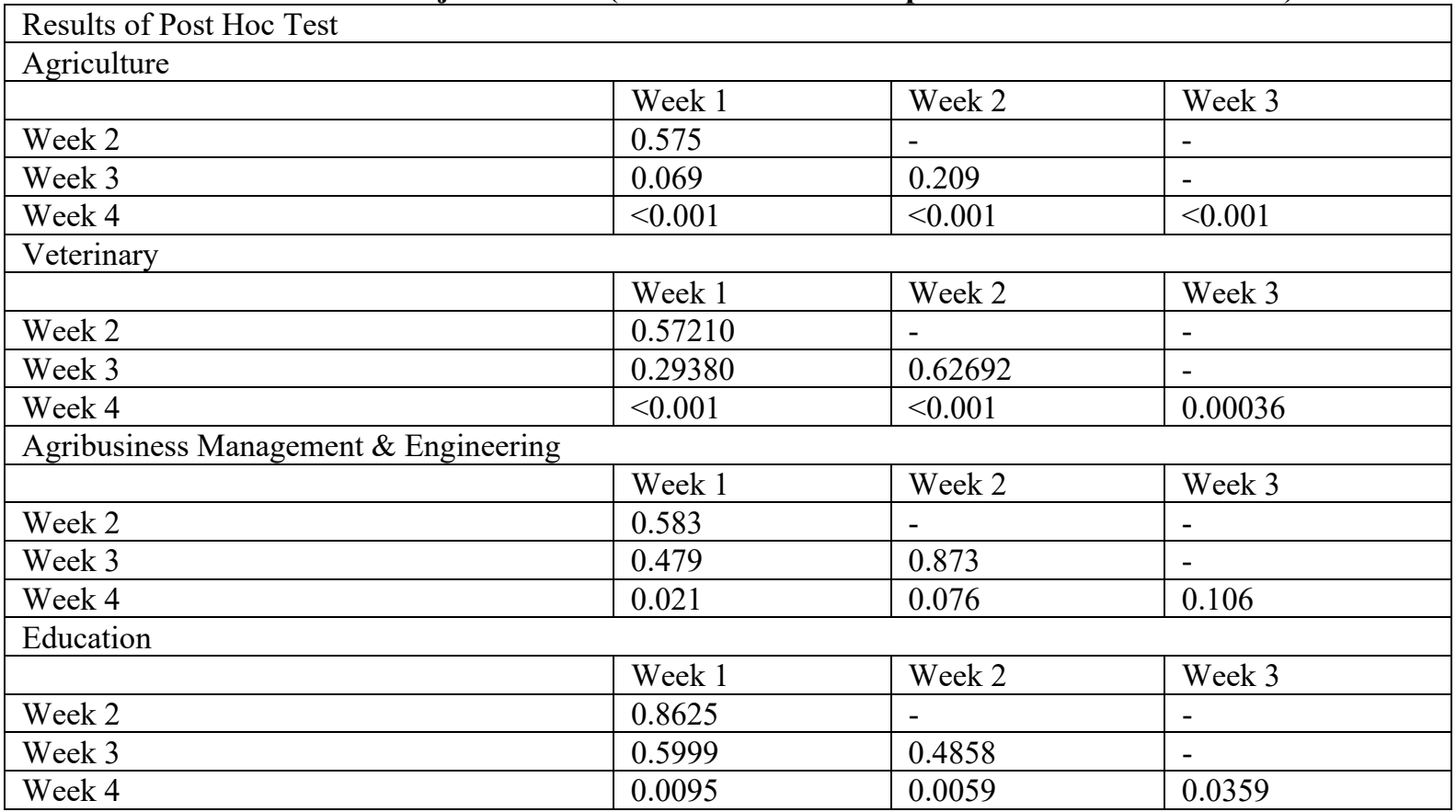

\section{Conclusion}

In this study, the learning behavior of the learners and their learning pattern in terms of login activities were calculated to determine the subject-domain based learning pattern in the MOOC platform. Stratified simple random sampling with proportional allocation was carried out for the study. In this study, first described the demographic characteristic of the learners and learning behavior in MOOC. Then, the paired sample t-test was employed to find 
out significant differences in the learning patterns of the learners based on their subject domain. The findings of this study revealed that the majority of the learners were male, doctorate degree holders, and from the agriculture subject domain. It may conclude that the male learners were highly aware of course and interested to participate in MOOC and agriculture domain learners were highly enrolled in the MOOC as compared to all other subject domain learners. Most of the learners were fall under the passive types of learners with their learning behavior which indicates their way of participating in the course. Majority of the learners were fall under moderate types of learners which indicates their interest to learn and seriousness about the course.

Paired sample t-test results indicated that there was no significant difference between the login pattern of agriculture and veterinary subject domain learners. However, there was a significant difference between ABM, engineering, and education domain learners' login patterns. It concluded that the agriculture and veterinary domain learners have similar learning pattern in MOOC. Whereas, agribusiness management and engineering domain learners were performing well with login pattern as compared to education domain learners. Likewise, there was a similar learning pattern in MOOC by the male and female learners of the agriculture and veterinary subject domain. ANOVA with factor replication result revealed that there is highly significance difference in group means for all subject domain in terms of no. of login in different weeks. Post hoc test result indicated that there is significant difference between the no. of logins in week four and other weeks for agriculture, veterinary, and education group. Whereas, there is significant difference between only no. of logins in week four and week one and all others are on par for agribusiness management $\&$ engineering group. The findings of this study contribute to a better understanding of learners' learning behavior and pattern in MOOCs. The learning behavior and pattern of learners are likely to prove the richest for improving the quality of learning and the learning environment.

\section{References}

Alraimi, K. M., Zo, H., \& Ciganek, A. P. (2015). Understanding the MOOCs continuance: The role of openness and reputation. Computers \& Education, 80, 28-38.

Anderson, A., Huttenlocher, D., Kleinberg, J., \& Leskovec, J. (2014). Engaging with massive online courses.WWW'14 Proceedings of the 23rd International Conference on World Wide Web,687-698. http://dx.doi.org/10.1145/2566486.2568042.

Basol, G., \& Balgalmis, E. (2016). A multivariate investigation of gender differences in the number of online tests received-checking for perceived self-regulation. Computers in Human Behavior, 58, 388-397.

Blagojević, M., \& Milošević, D. (2015, March). Massive open online courses: EdX vs Moodle MOOC. In Proc. 5th International Conference on Information Society and Technology, Kopaonik, Serbia (pp. 346-351).

Breslow, L., Pritchard, D. E., DeBoer, J., Stump, G., Ho, A. D., \& Seaton, D. (2013). Studying learning in the worldwide classroom: Research into edX's first MOOC. Research \& Practice in Assessment, 8(March 2012), 13-25. Retrieved fromhttp:/www.mendeley.com/catalog/studying-learning-worldwide-classroom-researchedxs-first-mooc/.

Christensen, G., Steinmetz, A., Alcorn, B., Bennett, A., Woods, D., Emanuel, E.J. (2013): The MOOC phenomenon: who takes massive open online courses and why? Available at SSRN 2350964.

Guo, P. J., \& Reinecke, K. (2014). Demographic differences in how students navigate through MOOCs. In Proceedings of the first ACM conference on Learning@, scale conference, pp. 21-30. ACM. http://dx.doi.org/10.1145/2556325.2566247.

Evans, B. J., Baker, R. B., \& Dee, T. S. (2016). Persistence patterns in Massive Open Online Courses (MOOCs). Journal of Higher Education, 87(2), 206-242. http://dx.doi.org/10.1353/jhe.2016.0006.

Hansen, J. D., \& Reich, J. (2015). Democratizing education? Examining access and usage patterns in massive open online courses. Science (New York, N.Y.),350(6265),1245-1248http://dx.doi.org/10.1126/science.aab3782.

Ho, A. D., Chuang, I., Reich, J., Coleman, C. A., Whitehill, J., Northcutt, C. G. and Petersen, R. (2015). HarvardX and MITx : Two years of open online courses fall2012-Summer 2014.SSRN Electronic Journal, 10,137.http://dx.doi.org/10.2139/ssrn.2586847.

Hood, N., Littlejohn, A., \& Milligan, C. (2015). Context counts: How learners' contexts influence learning in a MOOC. Computers \& Education, 91, 83-91.

Kahan, T., Soffer, T., \& Nachmias, R. (2017). Types of participant behaviourin a massive open online course. International Review of Research in Open and Distributed Learning: IRRODL, 18(6), 1-18.

Kizilcec, R. F., Piech, C., \& Schneider, E. (2013). Deconstructing Disengagement: Analyzing Learner Subpopulations in Massive Open Online Courses. In Proceedings of the Third International Conference on Learning Analytics and Knowledge.http://dx.doi.org/10.1145/2460296.2460330.

Kizilcec, R. F., \& Halawa, S. (2015). Attrition and Achievement Gaps in Online Learning. In Proceedings of the Second ACM Conference on Learning @ Scale. http://dx.doi.org/10.1145/2724660.2724680.

Liou, P. Y., \& Kuo, P. J. (2014). Validation of an instrument to measure students' motivation and self-regulation towards technology learning. Research in Science \& Technological Education, 32(2), 79-96. http://dx.doi.org/10.1080/02635143.2014.893235. 
Mukala, P., Buijs, J. C. A. M., \& Van Der Aalst, W. M. P. (2015). Exploring students' learning behaviourin moocs using process mining techniques. Department of Mathematics and Computer Science, University of Technology, Eindhoven, The Netherlands, 179-196.

Onah, D. F., Sinclair, J., Boyatt, R., \& Foss, J. (2014, November). Massive open online courses: learner participation. In Proceeding of the 7th International Conference of Education, Research and Innovation, (pp. 2348-2356.

Perna, L. W., Ruby, A., Boruch, R. F., Wang, N., Scull, J., \& Evans, C. (2014). Moving through MOOCs: Understanding the progression of users in Massive Open Online Courses. Educational Researcher, (December), 421-432. http://dx.doi.org/10.3102/0013189X14562423.

Pireva, K., Imran, A. S., \& Dalipi, F. (2015). User behaviouranalysis on LMS and MOOC. In 2015 IEEE Conference on e-Learning, e-Management and e-Services (IC3e) (pp. 21-26). IEEE.

Ramesh, A., Goldwasser, D., Huang, B., Daumé III, H., \& Getoor, L. (2013). Modeling learner engagement in MOOCs using probabilistic soft logic. In NIPS workshop on data driven education (Vol. 21, p. 62).

Santos, J. L., Klerkx, J., Duval, E., Gago, D., \& Rodríguez, L. (2014). Success, activity and drop-outs in MOOCs: an exploratory study on the UNED COMA courses. In Learning Analytics and Knowledge (pp. 98-102).

Seaton, D. T., Bergner, Y., Chuang, I., Mitros, P., \& Pritchard, D. E. (2014). Who does what in a massive open online course? Communications of the ACM, 57(4),58-65. http://dx.doi.org/10.1145/2500876.

Spyropoulou, N., Pierrakeas, C., \& Kameas, A. (2014). Creating MOOC Guidelines based on best practices. Edulearn14 Proceedings, 6981-6990.

Tharindu, R.L., Andrew, A.A., and Shirley, A. W. (2013). MOOCs: A Systematic Study of the Published Literature 2008-2012, http://www.irrodl.org/index.php/irrodl/article/view/1455/2531.

Tseng, S. F., Tsao, Y. W., Yu, L. C., Chan, C. L., \& Lai, K. R. (2016). Who will pass? Analyzing learner behaviors in MOOCs. Research and Practice in Technology Enhanced Learning, 11(1), 8.

Tucker, C., Pursel, B. K., \& Divinsky, A. (2014). Mining student-generated textual data in MOOCs and quantifying their effects on student performance and learning outcomes. The ASEE Computers in Education (CoED) Journal, 5(4), 84.

Vermunt, J. D., \& Donche, V. (2017). A learning patterns perspective on student learning in higher education: state of the art and moving forward. Educational Psychology Review, 29(2), 269-299.

Wang, X., Yang, D., Wen, M., Koedinger, K., \& Rosé, C. P. (2015). Investigating How Student's Cognitive Behaviourin MOOC Discussion Forums Affect Learning Gains. International Educational Data Mining Society.

Yukselturk, E., \& Top, E. (2013). Exploring the link among entry characteristics, participation behaviors and course outcomes of online learners: An examination of learner profile using cluster analysis. British Journal of EducationalTechnology,44(5),716-728. http://dx.doi.org/10.1111/j.1467-8535.2012.01339.x. 